Jurnal Ilmiah Farmasi 16(2) Agustus-Desember 2020, 96-104

ISSN: $1693-8666$

available at http://journal.uii.ac.id/index.php/JIF

\title{
The relationship between sosiodemographic factors and public knowledge of herbal medicines in two districts in Sleman Regency
}

\section{Hubungan faktor sosiodemografi dengan tingkat pengetahuan masyarakat tentang obat herbal di dua kecamatan Kabupaten Sleman}

\author{
Dian Medisa*, Hady Anshory, Putri Litapriani, Rezky Fajriyati M
}

Department of Pharmacy, Universitas Islam Indonesia, Yogyakarta, Indonesia

*Corresponding author: dianmedisa@uii.ac.id

\begin{abstract}
Introduction: The use of herbal medicines in the community is on the increase in both developing and advanced countries. Most people use herbal medicines through generations or based on experience. Therefore, it is necessary to analyse public knowledge of herbal medicine to support the appropriate and proper use of herbal medicines.

Objectives: To determine the relationship between sociodemographic characteristics and the level of public knowledge of herbal medicines in two districts in Sleman Regency.

Methods: Survey research was conducted for the people of Minggir and Cangkringan Districts, Sleman Regency. A sample of 240 respondents was taken through the cluster sampling method, and data was collected through a validated questionnaire. Respondents who scored higher than the mean were grouped into good knowledge, whereas those with less than or equal to the mean were in the category of poor knowledge. Data was analysed using the chi-square test.

Results: The majority of respondents were women (61.2\%) mostly aged $26-45$ years (46.7\%). The highest percentage of knowledge was in the domain of the side effects of herbal medicines (78.3\%), while the lowest knowledge was about how to use herbal medicines (32.1\%). Exactly 55\% respondents had good knowledge of all the domains about herbal medicines. The results of bivariate analysis showed that sociodemographic factors were insignificantly correlated with respondents' level of knowledge of herbal medicines ( $p>0.05)$.

Conclusion: There was no correlation between sociodemographic characteristics and knowledge of herbal medicines. Knowledge of herbal medicines can be increased by providing an education program based on the needs and conditions of the sociodemographic society.
\end{abstract}

Keyword: knowledge, herbal medicine, Sleman regency

\section{Intisari}

Latar Belakang: Penggunaan obat herbal $(\mathrm{OH})$ di masyarakat semakin meningkat, baik di negara berkembang maupun negara maju. Sebagian besar masyarakat menggunakan obat herbal secara turun temurun atau berdasarkan pengalaman. Oleh karena itu, perlu dilakukan analisis terhadap pengetahuan masyarakat tentang obat herbal untuk mendukung penggunaan obat herbal dengan tepat dan benar.

Tujuan: Untuk mengetahui hubungan sosiodemografi dengan tingkat pengetahuan masyarakat tentang obat herbal pada dua kecamatan di Kabupaten Sleman.

Metode: Penelitian survey yang dilakukan pada masyarakat Kecamatan Minggir dan Cangkringan, Kabupaten Sleman. Pengambilan sampel sebanyak 240 responden dilakukan dengan metode cluster sampling. Data diperoleh dari pembagian kuesioner yang telah tervalidasi. Responden yang memiliki skor di atas nilai rata- 
rata termasuk dalam kategori berpengetahuan baik, sedangkan jika dibawah atau sama dengan rata-rata termasuk kategori berpengetahuan buruk. Data dianalisis menggunakan uji chi-square.

Hasil: Mayoritas responden adalah wanita (61,2\%) dan usia paling banyak $26-45$ tahun $(46,7 \%)$. Persentase pengetahuan yang paling baik yaitu pada domain efek samping obat herbal $(78,3 \%)$, sedangkan pengetahuan yang terendah tentang cara penggunaan obat herbal $(32,1 \%)$. Lima puluh lima persen responden memiliki pengetahuan yang baik tentang obat herbal secara keseluruhan. Hasil analisis bivariat menunjukkan faktor sosiodemografi tidak berhubungan secara signifikan dengan tingkat pengetahuan responden tentang obat herbal $(\mathrm{p}<0,05)$.

Kesimpulan: Faktor sosiodemografi tidak berhubungan dengan tingkat pengetahuan tentang obat herbal. Pengetahuan tentang obat herbal dapat ditingkatkan melalui pemberian edukasi yang sesuai dengan kebutuhan dan kondisi sosiodemografi masyarakat.

Kata kunci: pengetahuan, obat tradisional, Kabupaten Sleman

\section{Latar Belakang}

Obat tradisional merupakan suatu bahan yang berasal dari bahan tumbuhan, bahan hewan, bahan mineral atau campuran dari bahan-bahan tersebut yang biasanya digunakan secara turun temurun untuk pengobatan, pencegahan penyakit, maupun pemeliharaan kesehatan (Kemenkes, 2017; Moreira et al., 2014). Saat ini penggunaan obat tradisional semakin meningkat baik di negara berkembang maupun negara maju. Masing-masing negara atau daerah memiliki kebiasaan yang berbeda-beda dalam penggunaan obat tradisional karena dipengaruhi oleh beberapa faktor seperti budaya, sejarah, dan sikap individu. Obat tradisional yang paling banyak digunakan di seluruh dunia adalah obat herbal atau obat yang berasal dari tumbuhan (Seyyedrassoli et al., 2017; Temitayo et al., 2017). Di Indonesia, sebanyak 59,12\% penduduk berusia di atas 15 tahun menggunakan jamu dan 30,40\% rumah tangga memanfaatkan pelayanan kesehatan tradisional (Kemenkes, 2013). Sebagian masyarakat menggunakan obat herbal tidak hanya untuk terapi tunggal tetapi dikombinasikan dengan terapi modern. Masyarakat meyakini bahwa obat herbal lebih aman, murah dan lebih manjur dibandingkan dengan obat modern, meskipun data ilmiah terkait keamanan dan efektifitas obat herbal belum cukup memadai. Masyarakat menggunakan obat herbal dalam bentuk ramuan dari bahan alam asli maupun produk jadi seperti suplemen (Belachew et al., 2017; Destiani \& Suwantika, 2015; Gitawati \& Handayani, 2008). Banyaknya penggunaan obat tradisional terutama obat herbal di masyarakat didukung oleh pemerintah dengan penyelenggaraan program pengembangan dan pemanfaatan tanaman obat keluarga (TOGA) sebagai upaya meningkatkan kemandirian masyarakat dalam mengatasi permasalahan kesehatan (Maryani \& Kusumawati, 2008). Dengan pemanfaatan obat herbal secara mandiri, maka masyarakat harus memiliki pengetahuan yang baik tentang obat herbal agar dapat menggunakannya dengan tepat sesuai kebutuhan.

Di Indonesia, penelitian tentang pengetahuan obat tradisional atau obat herbal masih sangat 
terbatas, sehingga perlu dilakukan penelitian terkait pengetahuan obat herbal. Penelitian ini bertujuan untuk mengetahui tingkat pengetahuan masyarakat tentang obat tradisional di wilayah Kabupaten Sleman dan hubungan sosiodemografi dengan pengetahuan.

\section{Metode Penelitian}

\section{a. Rancangan Penelitian}

Penelitian ini merupakan penelitian survey dengan rancangan cross-sectional di Kecamatan Minggir dan Cangkringan, Kabupaten Sleman pada Juni-Juli 2018. Penelitian ini telah mendapatkan ijin dari komite etik Fakultas Kedokteran Universitas Gadjah Mada dengan nomor KE/FK/0574/EC/2018.

\section{b. Sampel Penelitian}

Jumlah sampel penelitian sebanyak 240 responden yang dipilih dengan metode cluster sampling. Responden yang digunakan harus memenuhi kriteria inklusi yaitu, masyarakat berusia 1865 tahun, pernah atau sedang mengkonsumsi obat herbal dan bersedia menjadi responden. Responden dieksklusikan jika tidak mengisi kuesioner dengan lengkap dan jelas.

\section{c. Instrumen Penelitian}

Kuesioner terdiri dari dua bagian yaitu bagian satu tentang sosiodemografi dan bagian dua tentang pengetahuan. Informasi sosiodemografi meliputi jenis kelamin, usia, pendidikan terakhir, pekerjaan, dan penghasilan. Bagian pengetahuan obat herbal meliputi pengertian dan logo (3 pertanyaan), khasiat atau indikasi (7 pertanyaan), cara penggunaan (3 pertanyaan), dan efek samping obat ( 2 pertanyaan). Pilihan jawaban pada bagian pengetahuan obat herbal yaitu "benar" dan "salah".

Kuesioner disusun oleh peneliti berdasarkan review literatur dan telah diuji validasi maupun reliabilitas. Tahap validasi terdiri dari validasi konten dan uji coba. Pada tahap validasi konten, kuesioner direview oleh ahli di bidang obat herbal. Dari hasil validasi tersebut, terdapat perbaikan tata bahasa pada beberapa pertanyaan agar lebih jelas dan mudah dipahami. Proses selanjutnya yaitu uji coba kuesioner kepada 30 orang warga masyarakat yang sesuai kriteria inklusi dan warga tersebut tidak termasuk dalam responden penelitian. Uji coba kuesioner dilakukan untuk memastikan bahwa kuesioner tersebut telah dapat mengukur pengetahuan warga tentang obat herbal sesuai dengan tujuan penelitian. Adapun uji reliabilitas menggunakan rumus Cronbach's Alpha, diperoleh nilai sebesar 0,701. Kuesioner dikatakan reliabel karena nilai Cronbach's Alpha > 0,60 .

\section{d. Pengumpulan Data}


Peneliti meminta persetujuan kepada responden untuk mengisi kuesioner. Persetujuan dituliskan dalam inform consent. Responden mengisi kuesioner secara mandiri dengan didampingi oleh fasilitator.

e. Analisis Data

Jika responden menjawab dengan tepat mendapat skor=1, sebaliknya jika menjawab tidak tepat mendapat skor=0. Tingkat pengetahuan dibagi menjadi 2 kategori, yaitu baik dan buruk. Responden yang memiliki skor di atas nilai rata-rata termasuk kategori baik, sedangkan responden yang memiliki skor di bawah atau sama dengan nilai rata-rata termasuk kategori buruk. Analisis univariat untuk menghitung persentase sosiodemografi dan tingkat pengetahuan responden, sedangkan analisis bivariat (chi-square) untuk menganalisis hubungan faktor sosiodemografi dengan tingkat pengetahuan tentang obat herbal.

\section{Hasil dan pembahasan}

Penelitian dilakukan dengan tujuan untuk mengetahui tingkat pengetahuan masyarakat tentang obat herbal. Jumlah sampel yang diteliti sebanyak 240 responden. Adapun responden adalah warga yang berdomisili di wilayah Kecamatan Minggir dan Cangkringan, Kabupaten Sleman, Daerah Istimewa Yogyakarta. Seluruh responden dalam penelitian ini merupakan perwakilan dari tiap keluarga dan sudah pernah atau sedang menggunakan obat herbal. Profil karakteristik sosiodemografi responden tercantum dalam Tabel 1. Mayoritas responden adalah wanita (61,2\%), sedangkan pria $(38,8 \%)$. Hasil tersebut sejalan dengan pekerjaan yang didominasi oleh ibu rumah tangga (41,7\%). Usia responden yang paling banyak yaitu 26-45 (46,7\%) dan sebagian besar memiliki pendidikan SMA sampai perguruan tinggi (58,3\%).

Pengetahuan masyarakat tentang obat herbal perlu diteliti karena penggunaan obat herbal di masyarakat semakin meningkat, meskipun masih terdapat beberapa obat herbal yang belum terbukti aman dan efektif. Sebagian besar masyarakat menggunakan obat herbal berdasarkan pengetahuan, pengalaman, dan ketrampilan secara turun temurun. Dengan demikian, perlu dilakukan pengukuran terhadap pengetahuan masyarakat agar pemilihan maupun penggunaan obat herbal dapat dilakukan dengan tepat, sehingga terhindar dari efek yang berbahaya bagi tubuh (Gitawati \& Handayani, 2008; Moreira et al., 2014; Ningsih, 2016).

Pengetahuan diukur menggunakan kuesioner yang diberikan secara langsung kepada responden. Hasil tingkat pengetahuan obat herbal berdasarkan tiap domain pertanyaan tercantum dalam Tabel 2. Responden memiliki pengetahuan yang paling baik tentang efek samping obat herbal $(78,3 \%)$, sedangkan pengetahuan yang paling kurang yaitu cara penggunaan obat herbal $(32,1 \%)$. 
Sebagian besar responden juga telah mengetahui pengertian $(51,2 \%)$ dan khasiat $(63,3 \%)$ dari beberapa obat herbal. Selain itu, terdapat responden yang belum mengetahui bahwa logo obat herbal terbagi menjadi 3, yaitu logo jamu, logo obat herbal tersandar, dan logo fitofarmaka. Logo obat herbal penting untuk diketahui oleh masyarakat agar dapat memilih obat dengan tepat dan sesuai dengan kebutuhan.

Tabel 1. Karakteristik sosiodemografi responden

\begin{tabular}{lll}
\hline Karakteristik Sosiodemografi & n (\%) \\
\hline Jenis kelamin & Pria & $93(38,8)$ \\
& Wanita & $147(61,2)$ \\
\hline Usia & $18-25$ & $19(7,9)$ \\
& $26-45$ & $112(46,7)$ \\
& $46-65$ & $109(45,4)$ \\
\hline Pekerjaan & Pelajar & $8(3,3)$ \\
& IRT & $100(41,7)$ \\
& Petani & $53(22,1)$ \\
& guru & $3(1,3)$ \\
& lain-lain & $76(31,7)$ \\
\hline Pendidikan & $\leq$ SD & $41(17,1)$ \\
terakhir & SMP & $59(24,6)$ \\
& $\geq$ SMA & $140(58,3)$ \\
\hline Pendapatan & $<1000000$ & $172(71,7)$ \\
& $1000000-1500000$ & $47(19,6)$ \\
& $>1500000$ & $21(8,7)$ \\
\hline Keterangan : Jumlah responden $=240$ orang
\end{tabular}

Terdapat bermacam-macam obat tradisional yang digunakan oleh masyarakat untuk mengatasi berbagai kondisi kesehatan, seperti diare, sakit tenggorokan, sakit gigi, diabetes, hipertensi, kanker, obesitas, dan lain-lain (Kemenkes, 2017; Wassie et al., 2015). Oleh karena itu, masyarakat harus mengetahui khasiat obat herbal yang digunakan agar mendapatkan efek yang optimal. Pada domain khasiat obat herbal, diketahui persentase responden yang telah mengetahui khasiat jahe (99,6\%), bawang putih (79,6\%), dan kunyit (53,3\%). Sebanyak 47,1\% responden menganggap bahwa obat herbal lebih efektif untuk mengatasi penyakit kronis, dan obat herbal memiliki khasiat yang sama dengan obat modern $(32,9 \%)$.

Pada domain cara penggunaan obat herbal, mayoritas responden $(89,2 \%)$ telah mengetahui bahwa obat herbal tidak diminum bersamaan dengan obat modern. Namun, masih banyak responden $(46,7 \%)$ yang belum mengetahui bahwa sebaiknya obat herbal tidak dikonsumsi setiap hari, serta aturan penggunaan kunyit pada masa kehamilan. Kunyit diyakini keamanannya jika digunakan pada trimester kedua dan ketiga, karena sampai saat ini belum ada bukti klinis yang menunjukkan bahwa konsumsi kunyit dapat menyebabkan kelahiran prematur. Meskipun demikian, wanita hamil 
seharusnya menghentikan penggunaan kunyit satu minggu sebelum hari perkiraan lahir (Akram et al., 2010; Jaafari et al., 2016). Penggunaan obat herbal oleh masyarakat termasuk wanita hamil, masih banyak dilakukan. Oleh karena itu, perlu dipastikan bahwa masyarakat telah mengetahui cara penggunaan obat herbal dengan benar.

Tabel 2. Tingkat pengetahuan responden tentang obat herbal berdasarkan tiap domain pertanyaan

\begin{tabular}{lccc}
\hline \multicolumn{1}{c}{ Domain } & Skor Rata- & \multicolumn{2}{c}{ Pengetahuan n (\%) } \\
\cline { 3 - 4 } & rata \pm SD & Baik & Buruk \\
\hline Pengertian dan logo OH & $1,9 \pm 0,9$ & $123(51,2)$ & $117(48,8)$ \\
Khasiat OH & $3,9 \pm 1,1$ & $152(63,3)$ & $88(36,7)$ \\
Cara penggunaan OH & $2 \pm 0,8$ & $77(32,1)$ & $163(67,9)$ \\
Efek samping OH & $0,9 \pm 0,6$ & $188(78,3)$ & $52(21,7)$ \\
\hline
\end{tabular}

Keterangan : Jumlah total responden $=240$ orang

Responden yang memiliki tingkat pengetahuan tentang obat herbal dalam kategori baik sebesar 55\%. Pada penelitian sebelumnya, juga menunjukkan hasil serupa yaitu $67,7 \%$ responden memiliki tingkat pengetahuan yang baik tentang obat herbal (Oktarlina et al., 2018). Tingkat pengetahuan tentang obat herbal akan mempengaruhi sikap dan perilaku penggunaan obat herbal. Semakin tinggi pengetahuan, maka semakin tinggi frekuensi penggunaan obat herbal (Asmelashe et al., 2017; Seyyedrassoli et al., 2017). Pengetahuan masyarakat tentang obat herbal dapat ditingkatkan dengan pemberian edukasi oleh tenaga kesehatan.

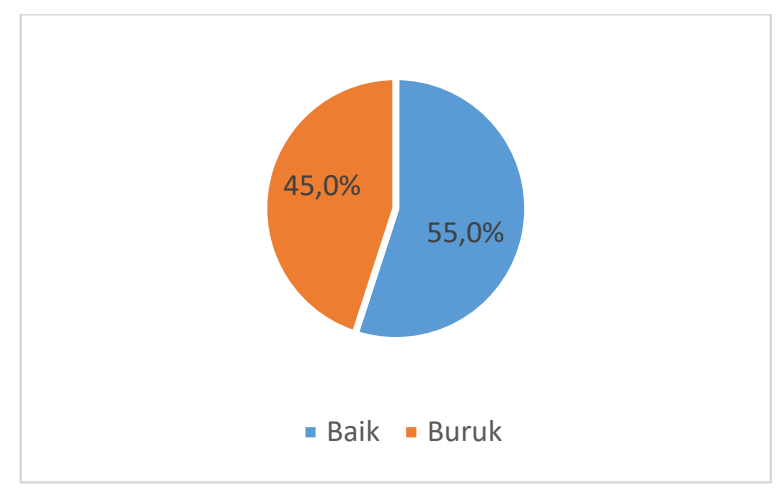

Gambar 1. Tingkat pengetahuan responden tentang obat herbal berdasarkan seluruh domain

Tabel 3. menunjukkan bahwa responden pria $(57,0 \%)$ memiliki tingkat pengetahuan tentang obat herbal yang sedikit lebih baik dibandingkan dengan wanita $(53,7 \%)$. Hal ini dapat disebabkan karena mayoritas responden laki-laki berpendidikan $\geq$ SMA. Kategori responden dengan tingkat pendidikan $\geq$ SMA memiliki persentase tingkat pengetahuan obat herbal yang lebih baik $(55,7 \%)$ 
dibandingkan responden dengan tingkat pendidikan < SMA (54,0\%). Seseorang yang memiliki tingkat pendidikan lebih tinggi cenderung lebih banyak mencari informasi informal secara mandiri (Alyahia et al., 2017).

Tabel 3. Hubungan sosiodemografi dengan tingkat pengetahuan masyarakat

\begin{tabular}{|c|c|c|c|c|}
\hline \multirow{2}{*}{\multicolumn{2}{|c|}{$\begin{array}{c}\text { Karakteristik } \\
\text { Sosiodemografi }\end{array}$}} & \multicolumn{2}{|c|}{ Tingkat Pengetahuan } & P-value \\
\hline & & $\begin{array}{l}\text { Baik } \\
\text { n (\%) }\end{array}$ & $\begin{array}{l}\text { Buruk } \\
\text { n (\%) }\end{array}$ & \\
\hline Jenis & Pria & $53(57,0)$ & $40(43,0)$ & 0.552 \\
\hline kelamin & Wanita & $79(53,7)$ & $68(46,3)$ & \\
\hline \multirow[t]{2}{*}{ Usia } & $\leq 45$ tahun & $73(55,7)$ & $58(44,3)$ & 0.897 \\
\hline & $>45$ tahun & $59(54,1)$ & $50(45,9)$ & \\
\hline \multirow[t]{2}{*}{ Pekerjaan } & Bekerja & $72(54,5)$ & $60(45,5)$ & 0.990 \\
\hline & Tidak bekerja & $60(55,6)$ & $48(44,4)$ & \\
\hline \multirow{2}{*}{$\begin{array}{l}\text { Pendidikan } \\
\text { terakhir }\end{array}$} & $<$ SMA & $54(54,0)$ & $46(46,0)$ & 0.677 \\
\hline & $\geq$ SMA & $78(55,7)$ & $62(44,3)$ & \\
\hline \multirow[t]{2}{*}{ Pendapatan } & $\leq 1,5$ juta & $121(55,3)$ & $98(44,7)$ & 0,502 \\
\hline & $<1,5$ juta & $10(47,6)$ & $11(52,4)$ & \\
\hline
\end{tabular}

Keterangan : signifikansi (chi-square $)=p<0,05$

Hasil analisis biavariat menunjukkan tingkat pengetahuan tentang obat herbal tidak berhubungan secara signifikan dengan karakteristik sosiodemigrafi, meliputi jenis kelamin, usia, pekerjaan, pendidikan, dan pendapatan $(p<0,05)$. Pada penelitian di Penang dan Merawi Town, tercantum bahwa tidak ada hubungan yang signifikan antara sosiodemografi (usia, pendidikan, dan pendapatan) dengan pengetahuan dan penggunaan obat herbal (Rahman et al., 2009; Wassie et al., 2015). Sebaliknya, penelitian di Iran menunjukkan hasil yang berbeda, yaitu terdapat hubungan secara siginifikan antara faktor sosiodemografi (usia, pendidikan, pekerjaan, dan pendapatan) dengan tingkat pengetahuan (Seyyedrassoli et al., 2017). Pendidikan tidak berhubungan dengan tingkat pengetahuan secara signifikan, hal ini kemungkinan karena informasi tentang obat herbal dapat diperoleh dari berbagai sumber informasi seperti TV, internet, buku, keluarga, ataupun tenaga kesehatan, tidak hanya dari pendidikan formal (Djabbar et al., 2017; El-Olemy et al., 2017).

\section{Kesimpulan}


Responden yang memiliki tingkat pengetahuan kategori baik sebanyak 55,0\%, sedangkan responden memiliki tingkat pengetahuan buruk 45,0\%. Faktor sosiodemografi tidak berhubungan secara signifikan dengan tingkat pengetahuan tentang obat herbal. Pengetahuan tentang obat herbal dapat ditingkatkan melalui pemberian edukasi yang sesuai dengan kebutuhan dan kondisi sosiodemografi masyarakat.

\section{Daftar pustaka}

Akram, M., Afzal, A., Khan, U., Abdul, H., Mohiuddin, E., \& Asif, M. (2010). Curcuma longa and Curcumin: A review article. Rom. J. Biol-Plant Biol., 55, 65-70.

Alyahia, O., Al-Bedah, A., Al-Dossari, D., Salem, S., \& Qureshi, N. (2017). Prevalence and Public Knowledge, Attitude and Practice of Traditional Medicine in Al-Aziziah, Riyadh, Saudi Arabia. British Journal of Medicine and Medical Research, 20, 1-14. doi:10.9734/BJMMR/2017/32749

Asmelashe, D., Mekonnen, G., Atnafe, S., Birarra, M., \& Belay, A. (2017). Herbal Medicines: Personal Use, Knowledge, Attitude, Dispensing Practice, and the Barriers among Community Pharmacists in Gondar, Northwest Ethiopia. Evidence-Based Complementary and Alternative Medicine, 2017, 7. doi:10.1155/2017/6480142

Belachew, N., Tadesse, T., \& Gube, A. A. (2017). Knowledge, Attitude, and Practice of Complementary and Alternative Medicine Among Residents of Wayu Town, Western Ethiopia. Journal of evidence-based complementary \& alternative medicine, 22(4), 929-935. doi:10.1177/2515690X17746547

Destiani, D., \& Suwantika, A. (2015). The Use of Herbal Supplements as One of Self Medications in Bandung. Indonesian Journal of Clinical Pharmacy, 4, 71-76. doi:10.15416/ijcp.2015.4.1.71

Djabbar, A., Musdalipah, M., \& Nurwati, A. (2017). Studi Pengetahuan, Sikap dan Tindakan Terhadap Penggunaan Obat Tradisional Bagi Masyarakat di Desa Sabi-Sabila Kecamatan Mowewe Kabupaten Kolaka Timur. Pharmauho, 3(1).

El-Olemy, A. T., Radwan, N. M., Dawoud, W. M., Zayed, H. A., Ali, E. A., Elsabbagh, H., Al-Dossari, D. S., Salem, S. O., \& Qureshi, N. A. (2017). Medical Students' Knowledge, Attitude and Practice towards Traditional and Complementary Medicine, Tanta City, Gharbiyah Governorate, Egypt. Journal of Complementary and Alternative Medical Research, 3(1).

Gitawati, R., \& Handayani, R. S. (2008). Profil konsumen obat tradisional terhadap ketanggapan akan addnya efek samping obat tradisional. Buletin Penelitian Sistem Kesehatan, 11(3), 6. doi:doi:10.22435/bpsk.v11i3 Jul.1876

Jaafari, M., Fotoohi, A., Razavi, N., \& Abdian, A. A. (2016). Herbal medicine in pregnancy. Advanced Herbal Medicine, 2(1), 13.

Kemenkes. (2013). Riset Kesehatan Dasar 2013. Jakarta: Kementrian Kesehatan Republik Indonesia

Kemenkes. (2017). Formularium Ramuan Obat Tradisional Indonesia. Jakarta: Kementrian Kesehatan Republik Indonesia

Maryani, H., \& Kusumawati, L. (2008). Upaya peningkatan pengetahuan tentang obat tradisional dan pemanfaatannya melalui pelatihan pada usila. Buletin Penelitian Sistem Kesehatan, 11(4), 5.

Moreira, D. D. L., Teixeira, S. S., Monteiro, M. H., De-Oliveira, A. C. A. X., \& Paumgartten, F. J. R. (2014). Traditional use and safety of herbal medicines. Brazilian Journal of Pharmacognosy, 24, 10.

Ningsih, I. Y. (2016). Studi Etnofarmasi Penggunaan Tumbuhan Obat Oleh Suku Tengger Di Kabupaten Lumajang Dan Malang, Jawa Timur. Pharmachy, 13(1).

Oktarlina, R. Z., Tarigan, A., Carolia, N., \& Utami, E. R. (2018). Hubungan Pengetahuan Keluarga dengan Penggunaan Obat Tradisional di Desa Nunggalrejo Kecamatan Punggur Kabupaten Lampung Tengah. JK Unila, 2(1), 5. 
Rahman, A. A., Sulaiman, S. A., Ahmad, Z., Salleh, H., Daud, W. N., \& Hamid, A. M. (2009). Women's attitude and sociodemographic characteristics influencing usage of herbal medicines during pregnancy in Tumpat District, Kelantan. Southeast Asian J Trop Med Public Health, 40(2), 330337.

Seyyedrassoli, A., Ghahramanian, A., \& Rahimlou, Z. (2017). The Relationship Between Knowledge and Attitude of Patients with Chronic Diseases Regarding Complementary Medicine. Iranian Red Crescent Medical Journal, 19.

Temitayo, O., Sariem, C., Dafam, D., O, O., Okwori, V., N, O., \& O, J. (2017). Knowledge, Attitude and Practice of Traditional Medicine Among People of Jos North Local Government Area of Plateau State, Nigeria. International Journal of Pharmacognosy and Phytochemical Research, 9. doi:10.25258/phyto.v9i10.10460

Wassie, S., Aragie, L., Taye, B., \& Mekonnen, L. (2015). Knowledge, Attitude, and Utilization of Traditional Medicine among the Communities of Merawi Town, Northwest Ethiopia: A CrossSectional Study. Evidence-Based Complementary and Alternative Medicine, 2015, 1-7. doi:10.1155/2015/138073 